COMPARATIVE ANALYSIS OF EPA COST-BENEFIT METHODOLOGIES

By

Leslie Poch Jerry Gillette John Veil

May 1998

Performed Under Contract No. W-31-109-ENG-38

\section{RECEIVED}

JUN 02999

c.8TI

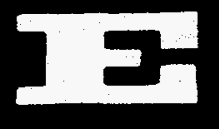

IT

13
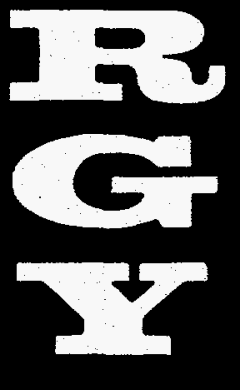

Argonne National Laboratory

Argonne, Illinois

\section{National Petroleum Technology Office U. S. DEPARTMENT OF ENERGY Tulsa, Oklahoma MASTER Loe}

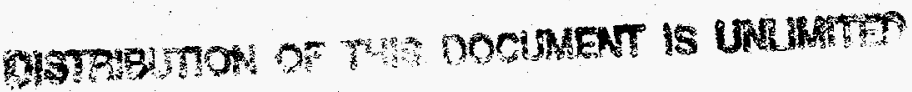




\section{DISCLAIMER}

This report was prepared as an account of work sponsored by an agency of the United States Government. Neither the United States Government nor any agency thereof, nor any of their employees, makes any warranty, expressed or implied, or assumes any legal liability or responsibility for the accuracy, completeness, or usefulness of any information, apparatus, product, or process disclosed, or represents that its use would not infringe privately owned rights. Reference herein to any specific commercial product, process, or service by trade name, trademark, manufacturer, or otherwise does not necessarily constitute or imply its endorsement, recommendation, or favoring by the United States Government or any agency thereof. The views and opinions of authors expressed herein do not necessarily state or reflect those of the United States Govemment.

This report has been reproduced directly from the best available copy.

Available to DOE and DOE contractors from the Office of Scientific and Technical Information, P.O. Box 62, Oak Ridge, TN 37831; prices available from (615) 5768401.

Available to the public from the National Technical Information Service, U.S. Department of Commerce, 5285 Port Royal Rd., Springfield VA 22161 


\section{DISCLAIMER}

Portions of this document may be illegible electronic image products. Images are produced from the best available original document. 
Comparative Analysis Of EPA Cost-Benefit Methodologies

By

Leslie Poch

Jerry Gillette

John Veil

May 1998

Work Performed Under Contract No. W-31-109-ENG-38

Prepared for

U.S. Department of Energy

Assistant Secretary for Fossil Energy

Nancy Holt, Project Manager

National Petroleum Technology Office

P.O. Box 3628

Tulsa, OK 74101

Prepared by:

Argonne National Laboratory

9700 S. Cass Avenue

Argonne, IL 60439 


\title{
COMPARATIVE ANALYSIS OF EPA COST-BENEFIT METHODOLOGIES
}

\author{
by \\ L. Poch, J. Gillette, and J. Veil

\section{EXECUTIVE SUMMARY}

In recent years, reforming the regulatory process has received much attention from diverse groups such as environmentalists, the government, and industry. With the change in the political makeup of Congress after the November 1994 elections, regulatory reform moved to the front of the legislative agenda of Congress. The 104th Congress passed two pieces of legislation dealing with the use of cost-benefit analysis in regulatory decision making: Small Business Regulatory Enforcement Fairness Act (H.R. 3136) and Unfunded Mandates Act (S.1).

A cost-benefit analysis can be a useful way to organize and compare the favorable and unfavorable impacts a proposed action might have on society. It can help decision makers understand the implications of various options. In a cost-benefit analysis, the costs and benefits of an action are determined, quantified, and assigned monetary values to the extent possible. The difference in monetary value between costs and benefits is then calculated. In a very simple sense, a project can be said to benefit society if the monetary value of its benefits is greater than that of its costs. However, in many cases, benefits are not easily valued, and so a decision cannot be based solely on the difference between the values of the benefits and costs. The decision maker must also take into account important issues that do not have a monetary value.

Since 1981, two Executive Orders have required the U.S. Environmental Protection Agency (EPA) and other regulatory agencies to perform cost-benefit analyses in support of regulatory decision making. Executive Order 12866 requires regulatory agencies to perform a cost-benefit analysis before promulgation of a significant regulation, which is typically one having an annual impact on the economy of $\$ 100$ million or more. The order further requires the regulator to select a regulatory approach in which the benefits "outweigh" the costs. However, if the statute governing a particular regulation specifically requires another selection criterion, this economic benefit selection criterion is overriden. At the EPA, a cost-benefit analysis is published as a document called a regulatory impact analysis (RIA).

This report reviews cost-benefit methodologies used by three EPA program offices: Office of Air and Radiation, Office of Solid Waste, and Office of Water. These offices were chosen because they promulgate regulations that affect the policies of this study's sponsor (U.S. Department of Energy, Office of Fossil Energy) and the technologies it uses. The study was conducted by reviewing 11 RIAs recently published by the three offices and by interviewing staff members in the offices. To draw conclusions about the EPA cost-benefit methodologies, their components were compared with those of a standard methodology (i.e., those that should be included in a comprehensive cost-benefit methodology). This study focused on the consistency of the approaches as well as their strengths and weaknesses, since differences in the cost-benefit methodologies themselves or in their application can 
cause confusion and preclude consistent comparison of regulations both within and among program offices.

This report concludes that in general, the EPA does a good job in performing cost-benefit analyses to support regulatory decisions. However, some problems were found in how the costbenefit methodologies are applied both within and across program offices. These problems include incomplete execution of a methodology, inconsistent use of parameters, and lack of external peer review (i.e., by an agency or organization outside the EPA). These problems occur for the following reasons: (1) language in the governing statute that prohibits use of economic criteria in selecting the regulatory approach, (2) time pressures caused by court-mandated decisions, (3) a lack of standard or consistent values for key parameters, and (4) a lack of data in some critical areas. Because these findings are based on only a sample of EPA RIAs, the problems should not be viewed as occurring in all EPA RIAs. However, the findings should be viewed as illustrating the kinds of problems that can occur in a cost-benefit analysis.

This report makes recommendations for enhancing cost-benefit analysis within the EPA. The recommendations include: (1) conduct more studies and discussions of alternatives (even those that the governing statute does not allow the EPA to consider) that might improve the economic efficiency of the regulation, (2) develop a checklist or common report format to remind the analyst to address all components in the methodology or explain why a component was not addressed, (3) standardize certain key parameters, and (4) obtain more extensive external peer review of RIAs.

Finally, the report makes recommendations on how the industry being regulated can help strengthen the deficient areas of a cost-benefit analysis. Data on direct compliance costs are usually readily available from industry. However, cost data on broader social issues such as impacts to health or the environment and other indirect costs are often difficult to value. Industries can help in this area by conducting some research on the effects of their product or technology on these broader issues. Industry can also help the cost-benefit process by addressing and quantifying risk trade-offs or substitutions and providing consistent data to the regulator. 


\section{INTRODUCTION}

For many years, diverse groups from nearly the entire political spectrum, such as environmentalists, the government, and business interests, have argued that the process of developing and issuing regulations should be reformed. With the change in the political makeup of Congress after the November 1994 elections, regulatory reform moved to the front of the agenda of the 104th Congress. Increased use of cost-benefit analysis in regulatory decision making was considered by Congress, both as part of separate legislation and as a requirement in the reauthorization of several major environmental statutes. The Small Business Regulatory Enforcement Fairness Act (H.R. 3136), which was signed into law in March 1996, gave Congress regulation-specific review authority before implementation of all regulations. Congress now has the power to disapprove significant regulations by enactment of a joint resolution. The Unfunded Mandates Act (S.1), signed into law in March 1995, requires federal regulatory agencies to conduct cost-benefit analyses of many new regulations. Other legislation considered but not passed by Congress in the spring of 1995 would have allowed cost-benefit analysis performed in support of proposed regulatory actions to be challenged in court or by petition to the regulator. Cost-benefit analysis is fast becoming an important issue in the regulatory arena.

A cost-benefit analysis is a useful way of organizing a comparison of the favorable and unfavorable impacts of proposed policies on society. Most economists feel that cost-benefit analysis should be used to help decision makers understand the implications of their choice. Even when information on benefits, costs, or both is highly uncertain (as is often the case with environmental regulations), cost-benefit analysis should play an important role in informing the decision making process (Arrow et al. 1996).

Since 1981, two Executive Orders have required that federal regulatory agencies perform a cost-benefit analysis before promulgation of a significant regulation. A regulation is defined as significant if it meets any one of four criteria set forth in the Executive Orders. The criterion that most commonly triggers "significant" status is that the regulation must have an annual impact on the economy of $\$ 100$ million or more. The first Executive Order (E.O.) requiring cost-benefit analysis was E.O. 12291, which was issued in 1981. With a change in the presidential administration in 1993, a new Executive Order, E.O. 12866, which was issued in September 1993, overrode the previous order.

A major difference between the two orders is in the way they specify how the regulatory agency should choose the preferred regulatory approach or alternative. E.O. 12866 specifies that the selected regulatory approach should "maximize net benefits to society (including potential economic, environmental, public health and safety, and other advantages; distributional impacts; and equity)." In contrast, E.O. 12291 specified that the selected regulatory approach's potential benefits to society should "outweigh" its costs, after recognizing that not all costs and benefits can be described in monetary or even qualitative terms. However, the statute governing the regulation could override this selection criterion if the statute requires another regulatory approach.

This study is a review of cost-benefit methodologies used by several program offices within the U.S. Environmental Protection Agency (EPA). This work was performed for the U.S. 
Department of Energy (DOE), Office of Fossil Energy. EPA program offices considered in this study were the Office of Air and Radiation (OAR), Office of Solid Waste (OSW), and Office of Water (OW). Within OW, the Office of Science and Technology, which promulgates effluent limitations guidelines, was the group that was studied. These EPA offices promulgate regulations that affect the energy industries as well as DOE facilities. This study focused on the consistency of the approaches as well as their strengths and weaknesses, since differences in the cost-benefit methodologies themselves or in their application can cause confusion and preclude consistent comparison of regulations both within and among program offices. Because it seems that cost-benefit analysis will be used increasingly in the regulatory decision-making process, consistency of approach is important.

This report is structured in the following manner. Section 2 is an overview of cost-benefit analysis. It describes the methodology and discusses important issues to consider when performing a cost-benefit analysis. Section 3 evaluates the cost-benefit methodologies used by three EPA program offices. Finally, Section 4 summarizes the study, draws conclusions, and recommends ways the regulated industry can strengthen the cost-benefit process. 


\section{OVERVIEW OF COST-BENEFIT ANALYSIS}

\subsection{Purpose of Cost-Benefit Analysis}

In the public sector, cost-benefit analysis is often used to assist in social decision making, including regulatory decisions. Its objective is to facilitate more efficient allocation of society's resources. A good cost-benefit methodology systematically identifies and measures the benefits and costs of a number of possible alternatives that could be used to achieve the goals of a project or program. Measuring these benefits and costs means not only quantifying them but also assigning them a dollar value to the greatest extent possible. Attaching a monetary value to an impact (which is commonly known as monetizing) attempts to show the cost of the impact on society or how much society should be willing to pay to avoid the projected impact. For example, the term "value of life" is often used in the literature. Although this term has been very controversial and somewhat misleading, it is used by economists to try to measure the price people are willing to pay for small changes in the probability of reducing different kinds of health and safety risks (Hahn 1996).

Because regulations affect the whole society, the total costs and benefits to society should be considered, not just those that apply to the regulated community. One way to compare each alternative course of action relative to the baseline or status quo is to find the net benefit, which can be defined as the difference between the monetized benefits and costs. Other ways to compare costs and benefits are discussed in Section 2.2.5. However, major regulatory decisions need not be bound by the strict cost-benefit test of choosing the alternative that has the greatest monetary net benefit to society. Many benefits may be qualified and even quantified but not monetized. Care should be taken to assure that monetized factors do not dominate important factors that are not monetized. In addition, other factors, such as equity within and across generations and distributional effects, may be important and should be considered in the decision-making process.

\subsection{Components of Cost-Benefit Analysis}

In recent years, the theoretical basis of cost-benefit analysis has become well-established and agreed upon by economists. However, implementing aspects of a cost-benefit analysis can be challenging. The five steps of cost-benefit analysis are to (1) develop the baseline and alternatives, (2) identify and analyze the benefits of each alternative, (3) identify and analyze costs of each alternative, (4) evaluate the benefits and costs, and (5) compare the benefits and costs. The discussion in the following subsections focuses on important considerations to take into account when performing cost-benefit analysis in support of regulatory decision making.

\subsubsection{Development of the Baseline and Alternatives}

Identification of a clear baseline is essential because the benefits and costs of each alternative must be measured against a baseline. The baseline should be the best assessment of what is likely to happen without a regulation. Some factors to consider when choosing a baseline are (1) steps the regulated community would take without the regulation, (2) compliance with current regulations, not only from the proposing agency but also from other government entities, and (3) compliance with regulations that are not currently in force but have a high likelihood of being enacted. If enactment 
of future regulations is uncertain, multiple baselines may be necessary. Consequently, developing a baseline can be a very challenging aspect of cost-benefit analysis.

A reasonable set of alternatives should be developed next. These alternatives should be different and span the range of realistic possibilities. Several approaches could be used to develop alternatives, including:

1. Performance-based standards that are written in terms of the result to be achieved but do not include detailed requirements for specific actions. For example, such standards could be stated in terms of a percentage reduction in the amount or toxicity of an emitted pollutant. Such standards could also be set on a plantwide, firmwide, or regional basis rather than for each pollutant source. This approach would allow the regulated parties to choose the most cost-effective way to comply with the regulation.

2. Standards based on different requirements for different segments of the regulated community. They might, for example, account for the size of the firm to be regulated. This approach may be taken so a burden is not placed on one segment of the regulated population that is disproportionate to or heavier than the damages that that segment creates.

3. Standards based on alternative levels of stringency that consider the relationship between stringency and the size and distribution of benefits and costs among different groups.

4. Market-based stondards that use economic incentives to achieve the desired result. These alternatives can include fees, subsidies, penalties, marketable permits, or offsets. Implementing these alternatives may require legislation.

5. Technology-based standards that specify the best available control technology or best practicable control technology be used on specific pollution sources. The regulatory agency would determine what technologies meet these requirements.

6. Alternatives other than direct regulation, such as voluntary actions taken by the regulated community.

Alternatives that set a control requirement on each pollutant source (also known as command and control) should not be the only ones considered. Alternatives that do not meet political, legislative, or budgetary constraints can be screened to determine if they are appropriate. However, reasons for eliminating alternatives should be clearly stated. Furthermore, although a statute may limit the final selection of a regulatory approach, the cost-benefit analysis should study other alternatives to show the consequences caused by statutory constraints (Office of Managernent and Budget [OMB] 1996).

\subsubsection{Identification and Analysis of Benefits}

Because regulations affect society as a whole, the analysis should include total social benefits. Benefits are defined as the outputs or results of compliance with a regulation, such as reductions in 
risks to human health and the environment. Sometimes the loss of a benefit can be considered to be either a negative benefit or a cost. For example, banning a product results in the loss of the benefit of using the product, after the mitigating effects of possible substitutes are accounted for. This loss of benefit to society is often viewed by some as a cost. It is important that these impacts be accounted for somewhere in the analysis, but they should be counted only once, as either a benefit or a cost.

Because of the dual way some regulatory impacts can be viewed, the method used to compare costs and benefits later in the cost-benefit analysis is very important. Several methods for comparing costs and benefits are discussed in Section 2.2.5. One method, net present value, minimizes the difficulties that can arise during cost-benefit comparisons because of this dilemma in classifying impacts.

The analysis should also account for potential negative benefits, or risk trade-offs, caused by a regulation. These can include effects on media other than the one regulated (commonly referred to as cross-media effects). For example, the amount of solid waste that is generated may increase when air emissions are being controlled, or a regulation that results in improvements in one area may also result in adverse health, safety, or environmental effects. These risk trade-offs should then be quantified and monetized.

In quantifying benefits, several important items should be considered. First, the most likely future chain of events should be used to quantify benefits to avoid over- or underestimating them. Neither the worst nor the most favorable case should be used in the baseline benefit estimate. Second, benefits for each alternative should be expressed as incremental values over the baseline and should be over a specific and consistent time period. A typical time period is the life span of capital equipment used to comply with the regulation. Also, health benefits (fatalities and illnesses avoided) that result from the use of pollution control equipment during the study period should be considered, even though they may occur many years after the study period. Third, impacts should be quantified by using methods that have undergone an independent or external peer-review process. If uncertainties exist in quantifying impacts, the values should be expressed as a range rather than as one number. Finally, the timing of impacts should be clearly stated and accounted for in the analysis, since an impact may occur many years after exposure to a substance. (This time lag in the onset of a disease or fatality is known as a latency period). Also, benefits should be monetized to the greatest extent possible by using methods that have undergone an independent peer-review process.

\subsubsection{Identification and Analysis of Costs}

Costs are defined as the value of goods and services lost to society as a result of regulatory compliance. Total social costs should be calculated, not only the costs to the regulated community. Total social costs are composed of direct compliance costs, government regulatory costs, deadweight welfare losses, adjustment costs, and other market costs. Direct compliance costs are those costs affecting the regulated sector, including capital and operation and maintenance (O\&M) costs for both existing regulated facilities and new ones that will be added during the study period. Increases in paperwork and monitoring costs caused by the regulation should also be included. Government regulatory costs include permitting, monitoring, enforcement, and other related costs expected to be incurred by the government after promulgation of a regulation. Deadweight welfare losses are a 
dollar measure of the difference between the value consumers place on output that is lost because of regulation and the cost of producing such output before the regulation. Adjustment costs are the value of resources that are displaced because of regulation-induced reductions in production and the cost of reallocating those resources. An example is the costs a firm incurs in lay-offs if production levels are reduced. However, a regulation may increase resource use in both primary and secondary markets; examples are increased demands for alternative products for pollution control equipment or increased O\&M requirements. These "negative costs" need to be included but should be counted only once, as either a cost or a benefit. Other market costs arise from adverse effects on product quality, productivity, innovation, and market structure.

Historically, direct compliance costs were considered the major cost component of regulatory compliance. However, one study concluded that the cost to society or indirect cost can be either higher or lower by a factor of three or four from the arithmetic total of direct compliance expenditures (Hazilla and Koop 1990). Consequently, because there can be a wide variance between direct and indirect costs, it is important to carefully consider and evaluate all of the indirect costs of a regulatory action.

Productivity has an effect on costs. The effects of environmental regulation on productivity have been analyzed in a number of studies (Office of Technology Assessment [OTA] 1994). Virtually all of the studies surveyed in the OTA report found that environmental regulations can contribute to a slowdown in productivity. Total factor productivity relates the outputs (value of the products the plant or firm produces) to all inputs to the firm, including capital, labor, purchased inputs, energy, and raw materials. On the other hand, environmental regulations can also increase productivity for a number of reasons. First, new production processes developed to comply with regulations might be more productive than the older ones (Barbera and McConnell 1990). Second, regulations may reveal outdated management practices and encourage managers to increase their attention on production processes and work practices.

The most likely future chain of events should be used to calculate costs to avoid over- or underestimating them. Costs for each alternative should be expressed as incremental values over the baseline for a specific and consistent time period. Costs should be developed by using standard costestimating techniques as well as by obtaining cost estimates from the regulated community. If uncertainties exist in estimating costs, they should be expressed as a range rather than as one number. Finally, the analysis should account for the timing of costs incurred over the study period.

\subsubsection{Evaluation of Benefits and Costs}

As noted in the previous two steps, costs and benefits can occur in different years during the study period. Therefore, to compare benefits and costs, it is not appropriate to simply add the values of benefits and costs accruing over time. The values of future costs and benefits should be moved backward in time, or discounted, relative to the current year (or other reference year) to obtain their present values. Discounting takes account of the fact that resources (goods or services) available in a given year are worth more than the identical resources available in a later year. One reason for this change in value is that a resource today is worth more than that same resource a year from now, if the resource is invested so as to produce a return on investment. 
Not only should future costs and benefits be discounted, but they should be corrected for any real escalation that may occur in the future value when compared with the current value. Real escalation reflects price increases that are independent of inflation and above it. A price change can result from resource depletion, increased demand, technology evolution, safety or environmental requirements, or other causes. Therefore, escalation in the future costs of such items as equipment purchases, maintenance, health care costs, etc., should be accounted for before discounting.

The choice of a discount rate is an important and rather contentious issue in cost-benefit analysis. Some economists argue that reductions in future health risks should never be discounted, because discounting may significantly reduce the apparent severity of future health effects and lead to the choice of an inequitable option (EPA 1987). For regulatory cost-benefit analysis, however, the discount rate is often specified by a government department and applied to both costs and benefits. The analyst should be careful to be consistent in the use of "apparent" or "real" escalation and "apparent" or "real" discount rate. In other words, inflation should be either consistently included or consistently excluded in the analysis of costs and benefits.

Another way of calculating the present values of both costs and benefits is to annualize the values. Annualization is done by first finding the present value of costs and benefits and then annualizing the value over the project lifetime. This procedure is similar to calculating mortgage payments. A project can then be evaluated by comparing the time stream of annual costs and benefits and determining the net benefits (i.e., benefits minus costs) each year. If the stream of benefits is constant over the lifetime of the project, comparing annualized costs to annualized benefits is analytically equivalent to comparing the present values of costs and benefits.

\subsubsection{Comparison of Benefits and Costs}

The final step in cost-benefit analysis is to compare the present value of benefits with the present value of costs for each alternative. Two techniques for making cost-benefit comparisons are the benefit-cost ratio technique and net present value technique. The benefit-cost ratio is the present value of benefits divided by the present value of costs. Ratios with a value greater than 1.0 indicate that the monetized benefits outweigh costs, while ratios less than 1.0 indicate that costs outweigh monetized benefits.

A problem inherent to the benefit-cost ratio technique is the dual way some regulatory impacts can be viewed (i.e., a negative benefit can be considered a positive cost). Consider a case in which a project's cost is $\$ 5$ and its net benefit is $\$ 30$. The net benefit is made up of a $\$ 40$ positive benefit to one affected party and a $\$ 10$ negative benefit to another affected party. If the net benefit is used to calculate the benefit-cost ratio, the ratio is $\$ 30 / \$ 5$ or 6 . If instead, the negative benefit is treated as a cost, the benefit-cost ratio becomes $\$ 40 /(\$ 5+\$ 10)$ or 2.7 . In these two cases, although the net benefit would remain unchanged, the benefit-cost ratio could be either 6 or 2.7. Benefit-cost ratios are thus subject to manipulation.

Consequently, the best cost-benefit comparison technique is the net present value technique. The net benefits of each alternative action relative to the baseline or status quo can be easily determined by computing the difference between the present value of monetized benefits and costs. The net present value is the present value of benefits minus the present value of costs. Using this 
comparison technique avoids manipulation of benefits and costs, because the net present value is always the same regardless of whether a benefit or a cost is considered to be positive or negative. In the earlier example, the net present value is $\$ 25$ if the $\$ 10$ is considered a cost or a negative benefit. This technique can also be used if benefits and costs are annualized by simply computing the difference between the annualized benefits and costs.

After finding and comparing the net present value of all alternatives, the decision maker should also consider the benefits that were not monetized before making a choice. Care must be taken to assure that monetized factors do not dominate important nonmonetized factors in decision making. There may be factors other than economic benefits and costs the decision maker will need to weigh before making the final choice. These factors include equity within and across generations, distribution of effects on important subgroups of the population, and potential for irreversible consequences (Arrow et al. 1996).

To deal with uncertainty in parameters, sensitivity studies should also be a part of any costbenefit analysis. Sensitivity studies help determine how the net present value changes if parameters deviate from their assumed or estimated values. A partial sensitivity analysis, which is most commonly used, focuses on the consequences of alternative assumptions about key parameters.

When many benefits cannot easily be monetized, the results of the cost-benefit analysis can be presented in the form of a cost-effectiveness (CE) analysis. The CE of a regulatory alternative is calculated by dividing the annualized cost of the alternative by a measure of its effectiveness. That measure can range from pollutant reduction (e.g., tons of pollutant removed) to ultimate improvements in human health or the environment (e.g., number of lives saved). Measuring the $C E$ of alternatives allows the decision maker to estimate how much "bang for the buck" each alternative delivers. Furthermore, a $\mathrm{CE}$ analysis can be performed whether or not benefits are monetized.

In summary, these steps comprise a cost-benefit analysis. Sources in the economic literature generally agree on how to estimate costs and benefits, which methods can be used, and the attributes and limitations of alternative methods. However, data, more than theory or methods, limit the quality of cost-benefit analyses (Rusin et al. 1996).

Another major consideration when performing a cost-benefit analysis is consistency. Each analysis should not only use consistent data or values but should also be performed to the same level of thoroughness or completeness. If the same level of completeness cannot be achieved in a specific cost-benefit analysis, any omission should be clearly stated, as well as the reason for the omission. Consistency is especially important if a cost-benefit analysis is used not only to choose among alternatives of a specific regulation but also to compare the effectiveness of different regulations and environmental programs. 


\section{EVALUATION OF EPA COST-BENEFTT METHODOLOGIES}

\subsection{Overview of How the EPA Conducts Cost-Benefit Analyses}

The EPA conducts full cost-benefit analyses only for "significant regulatory actions." According to E.O. 12866 (1993), a regulatory action is considered significant if it meets any one of the following four criteria:

1. Has an annual effect on the economy of $\$ 100$ million or more or adversely affects in a material way: the economy; a sector of the economy; productivity; competition; jobs; the environment; public health or safety; or state, local, or tribal governments or communities;

2. Creates a serious inconsistency or otherwise interferes with an action taken or planned by another agency;

3. Materially alters the budgetary impact of entitlements, grants, user fees, or loan programs or the rights and obligations of recipients thereof; or

4. Raises novel legal or policy issues arising out of legal mandates, the President's priorities, or the principles set forth in this Executive Order.

E.O. 12866 gives agencies wide latitude for conducting a cost-benefit analysis. In January 1996 , OMB issued additional guidance for preparing a cost-benefit analysis (referred to as an economic analysis). The OMB guidance document is not written in the form of a mechanistic blueprint because a good cost-benefit analysis cannot be written according to formula. Preparation of a high-quality analysis requires competent professional judgment, and different regulations may require different levels of analysis (OMB 1996). OMB recognizes that a statute may place limits on final selection of regulatory alternatives as well as on the allowable benefits or costs to be considered when selecting a final regulatory alternative. In such cases, agencies should analyze other regulatory alternatives that satisfy the philosophy and principles of the Executive Order to provide information to decision makers for judging consequences of statutory constraints (OMB 1996).

Cost-benefit analyses prepared by the EPA are supposed to be conducted in a manner consistent with E.O. 12866. To comply with the order, the EPA submits to OMB, for review, the cost-benefit analysis in the form of a report called a regulatory impact analysis (RIA) and a copy of the proposed regulation. In 1983, a guidance document was drafted by the EPA to help each EPA program office perform cost-benefit analyses for significant regulations (EPA 1983). Each program office can alter this guidance as they see fit when developing a cost-benefit analysis for a specific regulation (Patel 1996; Podar 1996). None of the three EPA program offices considered in this study has developed formal guidance of its own for preparing cost-benefit analyses required by the Executive Order. Completed RIAs may serve as models for new RIAs (Snyder 1996).

The EPA continues to use the guidance document as an interim guide for performing costbenefit analyses. Although EPA staff members feel the guidance satisfies the requirements of E.O. 12866 , they also feel that a revision is necessary to be more compatible with current views on 
conducting cost-benefit analyses (Snyder 1996). Also, there is a movement within the EPA to call the document required by E.O. 12866 an "economic analysis," but it will take time before the change is fully adopted.

\subsection{Evaluation of the EPA's Cost-Benefit Methodologies}

This study reviewed cost-benefit methodologies used by OAR, OSW, and OW in the EPA. These are the three offices that promulgate regulations that are likely to most affect DOE and the energy industries. Because these offices do not have their own formal guidance for conducting costbenefit analyses, interviews were held with staff members to determine how cost-benefit analyses are conducted. Eleven recently published RIAs (and support documents) were reviewed to determine how cost-benefit analyses were performed for specific regulations. A list of the RIAs, costeffectiveness reports, and other documents written to support RIAs that were reviewed for this study is shown in Table 1.

The review was done to determine the type of data that will need to be developed to help the EPA accurately evaluate the costs and benefits of energy technologies it might regulate. It is important to note the differences in the cost-benefit methodologies found both within and between EPA program offices. Such differences can lead to confusion and preclude consistent comparison of regulations. As EPA examines the relative effectiveness of different regulations and programs, it is important to use consistent cost-benefit analyses.

The EPA cost-benefit methodologies were evaluated by comparing them with (1) the general methodology and practices discussed in Section 2 and (2) guidance in the EPA and OMB documents. The EPA and OMB guidance documents are summarized in. Table 2. Differences and inconsistencies existed not only between the different EPA offices' methodologies (suggesting that they differ from the OMB and EPA guidance documents) but also between methodologies within an EPA program office. These differences and inconsistencies are discussed in Section 3.3. Because findings are based on only a sample of RIAs produced by EPA, the problems found should not be viewed necessarily as being widespread and found in all EPA RIAs. However, the findings do illustrate the kinds of problems that can occur in a cost-benefit analysis. 
TABLE 1 EPA RIAs and Other Support Documents Reviewed for the Study

\begin{tabular}{|c|c|c|}
\hline RIA Title & EPA Office & Date Published \\
\hline $\begin{array}{l}\text { Regulatory Impact Analysis for the Petroleum Refinery } \\
\text { NESHAP }\end{array}$ & $\begin{array}{l}\text { Office of Air and } \\
\text { Radiation }\end{array}$ & July 1995 \\
\hline $\begin{array}{l}\text { Economic Impact Analysis for the Petroleum Refinery NESHAP } \\
\text { - Revised Draft for Promulgation }\end{array}$ & $\begin{array}{l}\text { Office of Air and } \\
\text { Radiation }\end{array}$ & July 1995 \\
\hline Regulatory Impact Analysis of $\mathrm{NO}_{x}$ Regulations ${ }^{b}$ & $\begin{array}{l}\text { Office of Air and } \\
\text { Radiation }\end{array}$ & December 8, 1995 \\
\hline $\begin{array}{l}\text { Adverse Effects of Nitrogen Oxides }\left(\mathrm{NO}_{x}\right) \text { and Benefits of } \\
\text { Reduction }\end{array}$ & $\begin{array}{l}\text { Office of Air and } \\
\text { Radiation }\end{array}$ & December 1995 \\
\hline $\begin{array}{l}\text { Regulatory Impact Analysis of the Supplemental Proposed Rule } \\
\text { Applying Phase IV Land Disposal Restrictions to Newly } \\
\text { Identified Mineral Processing Wastes }\end{array}$ & $\begin{array}{l}\text { Office of Solid } \\
\text { Waste }\end{array}$ & December 1995 \\
\hline $\begin{array}{l}\text { Regulatory Impact Analysis of the Phase III Land Disposal } \\
\text { Restriction Final Rule }\end{array}$ & $\begin{array}{l}\text { Office of Solid } \\
\text { Waste }\end{array}$ & February 15, 1996 \\
\hline $\begin{array}{l}\text { Regulatory Impact Analysis of Final Effluent Limitations } \\
\text { Guidelines and Standards for the Offshore Oil and Gas Industry }\end{array}$ & Office of Water & January 1993 \\
\hline $\begin{array}{l}\text { Economic Impact Analysis of Final Effluent Limitations } \\
\text { Guidelines and Standards of Performance for the Offshore Oil } \\
\text { and Gas Industry }\end{array}$ & Office of Water & January 1993 \\
\hline $\begin{array}{l}\text { Cost-Effectiveness Analysis for Proposed Effluent Limitations } \\
\text { Guidelines and Standards for the Coastal Subcategory of the Oil } \\
\text { and Gas Extraction Point Source Category }\end{array}$ & Office of Water & February 1995 \\
\hline $\begin{array}{l}\text { Economic Impact Analysis for Proposed Effluent Limitations } \\
\text { Guidelines and Standards for the Coastal Subcategory of the Oil } \\
\text { and Gas Extraction Point Source Category }\end{array}$ & Office of Water & February 1995 \\
\hline $\begin{array}{l}\text { Regulatory Impact Analysis of Proposed Effluent Limitations } \\
\text { Guidelines and Standards for the Metal Products and Machinery } \\
\text { Industry (Phase I) }\end{array}$ & Office of Water & April 1995 \\
\hline
\end{tabular}

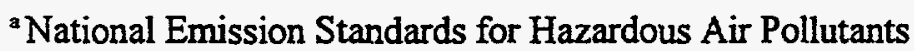

${ }^{b} \mathrm{NO}_{\mathrm{x}}=$ nitrogen oxides

- Specifically, the Office of Science and Technology 


\section{TABLE 2 Points to Cover in Cost-Benefit Analysis (from EPA and OMB Guidance)*}

Develop Baseline

1. Determine how world would look without regulation.

2. Account for current regulations from all regulators and for future regulations that have high likelihood of enactment.

3. If future is uncertain, develop several baselines.

Develop Alternatives

1. Span range of realistic possibilities (e.g., different levels of compliance, market/performance-based, voluntary actions).

2. Do not analyze only command and control alternatives.

3. Although governing statute may limit final selection of regulatory alternative, analyze other regulatory options as well.

\section{Identify and Analyze Benefits}

1. Address total social benefits, (i.e., benefits to all segments of society).

2. Address risk trade-offs and cross-media effects.

3. Calculate benefits as incremental over baseline; if uncertain, express as range, not single value.

4. Use key parameters consistently (e.g., study periods, exposure durations).

5. Clearly specify timing of benefits and account for latency period of fatalities and illnesses.

6. Monetize as many benefits as possible. Use standard, peer-reviewed methods.

Identify and Analyze Costs

1. Calculate total social cost, not just direct compliance costs.

2. Calculate costs as incremental over baseline; if uncertain, express as range, not single value.

3. Clearly specify timing of costs.

4. Use key parameters consistently (e.g., consistent study period for costs and benefits).

\section{Evaluate Benefits and Costs}

1. Discount time stream of all costs and benefits to the base year.

2. Use discount rate for both costs and benefits consistently.

3. Sum discounted costs and benefits to find present value of each.

4. Annualize costs and benefits, if desired.

Compare Benefits and Costs

1. Benefit-cost ratio technique is not recommended; it can be difficult to calculate and is subject to manipulation.

2. Net present value technique is recommended. This value equals present value of benefits minus present value of costs.

3. Cost-effectiveness technique is an acceptable method often used when benefits are not monetized.

4. Perform sensitivity studies on key parameters.

5. Peer review cost-benefit approach.

\footnotetext{
* Points noted represent a composite of items from each guidance document.
} 


\subsection{Differences in EPA Cost-Benefit Methodologies}

This section compares differences and inconsistencies in cost-benefit methodologies used by the three EPA program offices. Differences in four areas are discussed: (1) development of alternatives, (2) analysis of benefits, (3) analysis of costs, and (4) evaluation of benefits and costs. These areas parallel the steps discussed in Section 2 for developing a cost-benefit analysis.

Some program offices noted that differences and inconsistencies may occur because the language of some statutes has been interpreted as not allowing the regulatory decision process to consider certain alternatives, costs, or benefits. Consequently, these items may not be included in the cost-benefit analysis developed by the office. However, the analysis should still address these areas to give decision makers information for judging the consequences of statutory constraints (OMB 1996). Furthermore, omitting these areas from the analysis makes a direct comparison of the effectiveness of various regulations and environmental programs difficult.

\subsubsection{Development of Baseline and Alternatives}

All three program offices develop alternatives in a similar fashion. An EPA work group is formed to develop the regulation and to conduct all technical and analytical work. The work group is composed of staff from the office developing the regulation, other program offices, regional EPA offices, the Enforcement and Compliance Division, and others. All offices develop input for possible regulatory alternatives by meeting with representatives from environmental groups, state governments, and one or more regulated industries. It is felt that the OAR leads other offices in outreach activities, primarily because the Clean Air Act was reauthorized in 1990. Since then, OAR has accounted for $60 \%$ of the new EPA regulations (Eagles 1996). More outreach activities can be expected from other program offices as statutes are reauthorized. However, the Commission on Risk Assessment and Risk Management remains critical of EPA's outreach activities, stating that most EPA partnerships are with industry groups, not environmental groups (Omenn 1996). This commission, mandated under the 1990 Amendments to the Clean Air Act, considers issues related to the performance of human health risk assessments and the use of these assessments in regulatory decision making. The Commission seems to advocate that EPA offices include all interested stakeholders when developing regulatory alternatives.

When developing final effluent guidelines, the EPA is directed by the Clean Water Act (CWA) to consider only technology-based limits and not to consider impacts on water quality. Because of this statutory constraint, OW does not analyze market-based alternatives in cost-benefit analyses (EPA 1993a). Since the scope of the alternatives considered in the RIA is narrowed because of the statute, OW's methodology does not strictly adhere to OMB or EPA cost-benefit guidelines. Although the CWA does not allow the EPA to select a market-based alternative as the final effluent guideline, OMB guidance states that some analysis of these other regulatory alternatives should be performed to determine the effect this constraint has on regulatory efficiency.

In developing a baseline, all offices account for current regulations of their office as well as those of other program offices. The offices stated they may even develop several baselines, depending on the status of state, local, or future federal regulations in the approval process (Ballard 
and Luben 1996; Eagles 1996; Patel 1996). Therefore, baseline development appears to be a strong point in all of the program offices' cost-benefit methodologies.

\subsubsection{Analysis of Benefits}

There are several differences in the ways in which the three EPA program offices address issues related to monetization of benefits, duration of exposure to contaminants, and risk trade-offs. Both OAR and OW monetize benefits to the extent data are available. OSW, however, does not monetize benefits, such as avoided cancers, even though it does calculate the number of cancers that would be avoided by a given alternative. OSW stated that because the Resource Conservation and Recovery Act (RCRA) is based on risk reduction and does not allow the regulatory decision process to balance costs and benefits, monetization of avoided cancer deaths is not performed (Ballard and Luben 1996). Consequently, because of this omission, the net present value of costs and benefits cannot be determined from the results of the cost-benefit analysis, and the methodology cloes not adhere to OMB and EPA guidelines. Even though RCRA does not require monetization of cancer benefits, OSW could provide a better comparison of costs and benefits of each regulatory alternative by monetizing those benefits. This would also allow the office to satisfy the philosophy and principles of the E.O.

The introductory section of one RIA recently prepared by OAR (EPA 1995a) noted that the benefits of a proposed regulatory action would be discussed. However, the actual analysis was contained in a separate supporting document that was not referenced in the original RIA (EPA 1995b). According to the EPA, it is not uncommon for the information needed to evaluate the costs and benefits of a proposed rule to be contained in several different documents. EPA staff acknowledge this is an awkward means of communicating information on costs and benefits and hope to take steps to limit this unnecessary confusion. However, publishing separate support documents as part of the overall analysis is not confusing if all documents are clearly referenced.

A review of two RIAs recently developed by OSW revealed inconsistencies in the contaminant exposure durations used in the risk assessment models. In one RIA (EPA 1996), an exposure duration of 30 years was used, while the other (EPA 1995c), used an exposure duration of 9 years. Both values came from the Exposure Factors Handbook (EPA 1989). The 30-year value is the 90th percentile (high-end exposure) for residence time in one location, while the 9-year value is the 50th percentile (central-tendency exposure). No justification was given in either RIA for the use of one value over the other. To improve comparative analyses, the same values should be used for all RIAs unless very specific conditions dictate using a unique exposure duration. The high-end exposure can be used for an estimate of a maximally exposed actual person (Commission on Risk Assessment and Risk Management 1996). Also, the EPA has recently supported the use of central-tendency values to estimate an average population exposure (EPA 1991). If time and resources allow, calculations should be made for both exposures to determine sensitivity of results to variations in exposure. Although this weakness was noted in only one application of the OSW cost-benefit methodology, further reviews should be performed to determine if this inconsistency exists in other EPA program offices.

Valuing ecological benefits is an area the program offices themselves believe is deficient. The data for valuing the benefits of nonuse and ecological diversity are lacking (Clark 1996; Eagles 1996). 
Consequently, a complete monetization of benefits cannot be performed. However, the EPA's Science Policy Council has recently convened a social sciences work group to study valuation not only of ecological effects but also noncancer health effects (Risk Policy Report 1996). The valuation of ecological benefits is still in its infancy, but the EPA hopes the work group will make some progress in this area.

Risk trade-offs are addressed in varying degrees by all three program offices. A shortcoming exists in the OSW methodology, since the risks resulting from the transportation of hazardous wastes are not addressed in the cost-benefit methodology (Ballard and Luben 1996). The OSW staff members recognize this shortcoming, for which they have been criticized by OMB. Historically, they have not considered transportation risks, since such risks are not under the purview of RCRA. Because hazardous waste alternatives could involve the extensive use of transportation, it may be valuable to consider transportation risks in the methodology. OSW believes that transportation data exist and that such an analysis would not be difficult to perform (Ballard and Luben 1996). Although this shortcoming was only noted for the OSW cost-benefit methodology, further reviews should be done to determine if other EPA program offices neglect some potentially important countervailing risks.

\subsubsection{Analysis of Costs}

As noted in Section 2, one contributor to the total social cost of a regulatory alternative is the direct compliance cost. To calculate this cost, each EPA office uses models containing extensive industry cost data. Compliance cost estimates are also obtained from questionnaires sent directly to regulated industrial facilities and by soliciting information from technology vendors (Patel 1996). Cost estimates obtained from industry are carefully reviewed to assure accuracy (Ballard and Luben 1996; Eagles 1996). Additional monitoring and paperwork requirement costs are also factored into the compliance cost. This basic process is consistently practiced by all three EPA offices.

However, estimating the total social cost of a regulation does not appear to be done consistently within EPA. Some of the RIAs reviewed accounted for total social costs, such as changes in consumer and producer surplus, while others included only direct compliance costs. Also, none of the studies appeared to examine the effect of the regulation on productivity. The offices attributed these omissions largely to a lack of data. One RIA studying effluent guidelines in the offshore oil and gas industry (EPA 1993a) went so far as to quantify the loss in producer surplus (in barrels of oil equivalent) as a result of compliance with an alternative but did not monetize the loss, even though the unit cost (i.e., cost of a barrel of oil) was given in the report. In some cases, a regulation affected such a broad range of dissimilar industries that compiling the necessary data would be too costly or time consuming. The offices stated that cost-benefit analyses for regulations affecting only a single industry or several similar industries were more likely to have total social costs calculated. This inconsistency in the application of the methodology cuts across all program offices surveyed.

General equilibrium models can be used to calculate total social costs of a regulation. These models can be difficult and expensive to use, particularly if additional model construction or modification is required. Because of the complexity and cost, regulators are unlikely to make general equilibrium models a routine part of an RIA. However, analysts can often make good approximations 
by using existing data, models, and ranges of assumptions about certain costs and behaviors (Rusin et al. 1996).

\subsubsection{Evaluation of Benefits and Costs}

A cost-benefit evaluation consists of estimating the full stream of benefits and costs over the study period and calculating the net present value of this stream. However, there are a number of inconsistencies and shortcomings in the way that EPA program offices perform this step in their costbenefit methodologies. First, a full time stream of costs and benefits is not always shown. One RIA reviewed showed the costs and benefits for only the first and last years of the study period (EPA 1993a). Costs and benefits for the intervening years were not shown. Consequently, the net present value of the alternatives analyzed in this RIA could not be calculated. Hahn (1996) has also observed that the full time stream of costs and benefits is not shown in some RIAs.

Second, in all of the RIAs reviewed, the time stream of costs and benefits is not shown as a single net present value but is annualized over the study period. Annualization is an equivalent technique to net present value, but none of the EPA methodologies considered latency effects when annualizing costs and benefits. For example, if an alternative was shown to avoid 70 deaths over 70 years, this was shown as an average of one death avoided each year. In reality, the first cancer death may not occur for 20-30 years. Consequently, benefits can be overstated when latency is not considered. The effect of latency does not appear to be addressed by any of the EPA offices; hence, none of the methodologies adhere to the OMB and EPA guidance in this area. Hahn (1996) has also observed that latency effects are not considered in most RIAs.

Use of discount rates is another area in which inconsistencies occur. All of the offices surveyed stated that they derive discount rates from OMB Circular A-94, Guidelines and Discount Rates for Benefit-Cost Analysis of Federal Programs (OMB 1992); however, they appeared to apply them inconsistently in actual practice. OW used one discount rate for costs and a different one for benefits (Patel 1996), while OAR and OSW used the same discount rate for both costs and benefits (Ballard and Luben 1996; Eagles 1996). Although there are valid arguments for using the same discount rate or using different discount rates for costs and benefits, all EPA program offices should use the same methodology so that consistent comparisons can be made. Also, EPA guidance states that under most circumstances, discounting costs by one rate and benefits by another should be avoided (EPA 1983). Inconsistency in the use of discount rates has also been noted by Hahn (1996).

Finally, an RIA does not undergo an external peer review before being submitted to OMB. (An external peer review is done by an agency or organization other than the one doing the study). The program office writing the RIA is responsible for its content (Snyder 1996). Although an internal peer review once existed at EPA, it has been dismantled (Hopkins 1996), and an external peer review process has not been fully established, according to a recent Government Accounting Office report (ENR 1996). However, in light of legislation considered in the 104th Congress (namely, H.R. 9), which would require external peer review of regulatory programs, EPA should consider fully implementing such a program. Using peer-reviewed methods would add to the quality and credibility of the analysis and allow more consistent comparisons between regulations and programs to be made. 


\section{FINDINGS AND CONCLUSIONS}

\subsection{Summary of Findings}

After reviewing RIAs and conducting interviews with EPA program office staff, we conclude that the EPA has established a solid framework for performing cost-benefit analyses that support regulatory decision making. For more than 15 years, the EPA has conducted these analyses to comply with E.O. 12291 and E.O. 12866. It has relied upon guidance issued by OMB as well as internal EPA guidance. The investigations conducted to prepare this report have indicated that the EPA has generally put forth a conscientious effort to assure that its cost-benefit analyses use the best data and analytical techniques. However, some differences and inconsistencies exist in the costbenefit methodologies used by the different EPA program offices. Shortcomings in EPA cost-benefit analyses can be grouped into three areas: (1) incomplete execution of the methodology, (2) inconsistent use of standard parameters, and (3) lack of external peer review. These shortcomings and their prevalence across program offices are summarized in Table 3 and discussed below.

\subsubsection{Incompleteness of Methodology}

Execution of methodologies was found to be incomplete in several areas. First, the development of alternatives was sometimes incomplete. For example, OW did not analyze marketbased alternatives for regulations related to effluent guidelines because the CWA does not allow EPA to select this type of alternative for the final regulation. Second, benefits were sometimes not monetized. For example, OSW did not monetize benefits because RCRA does not allow the regulatory decision process to compare costs and benefits. These examples illustrate how a statute can influence the execution of a methodology. Third, sometimes documents containing supporting analysis for an RIA were not referenced in the RIA. For example, although the benefits of a proposed regulation were detailed in a supporting document, that document was not referenced in an OAR RIA.

Also, some of the cost-benefit analyses reviewed failed to calculate total social costs. This inconsistency appeared in all program offices surveyed. Reasons given for not calculating total social costs were either that data were lacking or that compilation of the necessary data would be too costly or time-consuming. However, some studies have shown that the indirect costs of a regulation can contribute as much or more to total social costs as the direct compliance cost (Hazilla and Koop 1990).

Failure to show the full time stream of costs and benefits is an example of another area in which an analysis was found to be incomplete. This omission was discovered in only one of the eleven RIAs reviewed, so further investigation would be useful to determine how often it occurs. Also, some methodologies used by each of the program offices studied do not consider latency effects of disease. Consequently, benefits may be overestimated, and the RIA will not adhere to OMB and EPA cost-benefit guidance. Failure to show the full time stream of costs and benefits and failure to consider latency effects of disease were observed by Hahn (1996) in his study of RIAs. 
The valuation of ecological benefits was found to be another problematic area in the EPA cost-benefit analyses reviewed. Paucity of data was the main reason given by the program offices for this deficiency. A complete quantification or monetization of benefits cannot always be performed when data valuing ecological benefits are lacking. However, the EPA is currently taking steps to develop these data (Risk Policy Report 1996).

Finally, failure to address risk trade-offs is another example of incomplete analysis that was discovered. OSW has not addressed transportation risks in its cost-benefit applications. Although other offices state that they do consider countervailing risks, further investigation is needed to determine how rigorously this work is performed.

\subsubsection{Inconsistent Use of Parameters}

Exposure durations have been used inconsistently. Within the OSW, one RIA used an exposure duration at the 90th percentile (or high-end exposure), while another RIA for a similar regulation used an exposure duration corresponding to the 50th percentile. No justification was given for using one value over another. This discrepancy was noted in one of the eleven RIAs reviewed; further investigation could determine the extent to which this inconsistency occurs throughout EPA. It appears that EPA has not specified standard practices to ensure the consistent and appropriate selection of exposure levels used in RIAs.

Discount rates have also been used inconsistently. All offices state that they refer to OMB guidance for discount rates, but some use the same discount rate for both costs and benefits, while others use one rate for costs and another for benefits. The EPA should standardize the use of discount rates across all offices or provide case-by-case justification for using alternative discount rates.

\subsubsection{Lack of External Peer Review}

The lack of external peer review is one shortcoming that cross-cuts all three program offices. If peer review were conducted regularly, some of the aforementioned shortcomings might be identified and corrected before analyses are published. Although the EPA apparently has a mechanism in place for external peer review, it appears to not be fully implemented (ENR 1995). Implementation of such a program would help solve some of the shortcomings as well as adding consistency and credibility to analyses. Furthermore, judging by the legislation considered by the 104th Congress (such as S. 343), external peer review may soon be required by law.

\subsubsection{Conclusions}

In summary, consistency is a major consideration in performing a cost-benefit analysis. Consistent data and values should be used, and each analysis should be performed to the same level of thoroughness or completeness. Regulatory reform requires that analyses be performed consistently to ensure that the best decisions about specific regulatory actions are made within and across program offices. 


\subsection{Recommendations}

A number of recommendations can be followed to correct the differences and inconsistencies in EPA cost-benefit methodologies noted in this study. First, incompleteness in executing the methodologies used was partially a result of statutory requirements. Although a change in statutory language would correct this shortcoming, this is not a solution over which EPA has direct control. However, when the final selection of the regulatory approach is limited by the governing statute, OMB guidance recommends that other regulatory options still be analyzed (OMB 1996). In fact, EPA's own guidance (EPA 1983) recommends that market-oriented regulatory alternatives be analyzed, whether or not they are explicitly authorized in EPA's legislative mandate.

Given the reality of the EPA budget and frequent court-ordered deadlines to publish rules, performing a thorough analysis of alternatives that cannot be selected for the final rule may be difficult. A possible option would be to address these alternatives in a qualitative fashion and state whether or not the economic efficiency of the regulation would be improved if these alternatives could be considered in the decision-making process. This option would provide decision makers with information on consequences of statutory constraints. It could also provide the public and legislators with the information they need to effect statutory change.

Second, because some inconsistencies occurred only in some RIAs, a checklist or common report format might be able to correct this problem. Since many new RIAs are based on past RIAs, omissions that may have occurred in the previous analyses may continue to occur in the new RIAs. A checklist would help to remind analysts of all the components that should be included in the methodology. A checklist is currently used by Australian regulators in developing their regulatory documentation (Hopkins 1996). Additionally, a common report format would make it easier to identify missing pieces of an analysis and make the analysis easier for stakeholders to understand. The EPA Office of Pollution Prevention and Toxics has developed a document on guidance for its RIAs (EPA 1993b) that not only specifies the format of the RIA but also details how the cost-benefit methodology should be performed and common key parameters that should be used.

Third, since inconsistencies occurred when common parameters were used, standardization of these parameters would correct this problem. For example, the EPA should standardize the selection of exposure levels used in RIAs and clearly state why a level was chosen. Both high-end and central-tendency exposures can be used to represent specific segments of the population exposure distribution. EPA should make calculations for both exposures to determine the sensitivity of the results to variations in exposure. Also, because latency effects were not considered in the methodologies, EPA should establish average latency periods for diseases. Standardizing latency periods was done in a recent study of RIAs by Hahn (1996).

Finally, more extensive external peer review of RIAs is needed. Peer review would help to identify problems early in the process and bring a higher level of consistency to the cost-benefit evaluation process. Consistency of analysis is needed if regulatory reform is to be achieved. The EPA itself has advocated an external peer review process and should implement it as soon as possible. 


\subsection{Strengthening Cost-Benefit Analysis through Industry Involvement}

The industry being regulated can provide information to improve cost-benefit analysis and make the regulatory process less contentious. Although a cost-benefit analysis is the regulator's responsibility, industry is most knowledgeable about the technology or product and can provide valuable support to the regulator. Because inadequate data can impede an agency from performing a thorough cost-benefit analysis, industry can focus some of its own research to fill in data gajss. Typically, industry comments on RIAs focus on direct compliance costs and less frequently on broader social or indirect costs. Industry can focus more attention and research on broader costbenefit considerations. These can include health or environmental improvements, losses or gains in consumer and producer surplus, and other indirect costs. These additional considerations should also be monetized to the extent possible.

Industry can offer the regulator comments on risk trade-offs. Risk trade-offs can include items such as changes in quantities of emissions not addressed by the proposed regulation, changes in the health and safety of workers using the product or technology, changes in impacts on special subgroups of the population, changes in intergenerational impacts, and others. Again, attaching a monetary value to these changes will be beneficial to the cost-benefit analysis.

Industry can also assist by providing consistent data to the regulator. This means providing data in consistent units and using consistent time frames andl exposure level assumptions. Providing information on timing of impacts is also important to calculate net present value correctly.

Finally, since a cost-benefit analysis developed by the EPA can be based on not only the RIA report but also supporting documents, it is important for the regulated industry to review all documents written in support of the proposed regulation.

By focusing on weaknesses in the cost-benefit process and providing information to address these areas, the regulated industry can help make the regulatory process less contentious. 
TABLE 3 Summary of Findings in Study of EPA Cost-Benefit Methodologies ${ }^{\mathrm{a}}$

\begin{tabular}{ll}
\hline \multicolumn{1}{c}{ Finding } & \multicolumn{1}{c}{ Description } \\
\hline Narrow scope of alternatives & $\begin{array}{l}\text { Alternatives analyzed limited only to those the } \\
\text { statute allows to be considered in selecting the } \\
\text { final regulation. }\end{array}$ \\
Failure to reference necessary documentation & $\begin{array}{l}\text { One RIA noted benefits would be discussed, but } \\
\text { did not provide a reference for the document } \\
\text { containing the analysis. }\end{array}$ \\
$\begin{array}{l}\text { Failure to fully analyze benefit } \\
\text { and risk trade-offs }\end{array}$ & $\begin{array}{l}\text { Risks associated with transport of hazardous } \\
\text { waste were not considered. }\end{array}$ \\
$\begin{array}{l}\text { Failure to monetize nonuse and ecological } \\
\text { diversity benefits: by EPA office }\end{array}$ & $\begin{array}{l}\text { Number of cancer deaths avoided by } \\
\text { implementing regulatory alternatives were } \\
\text { calculated but not monetized. }\end{array}$ \\
$\begin{array}{l}\text { Failure to monetize nonuse and ecological } \\
\text { diversity benefits: by EPA in general }\end{array}$ & $\begin{array}{l}\text { Nonuse and ecological diversity benefits are } \\
\text { generally not monetized in RIAs because of lack } \\
\text { of data. }\end{array}$ \\
Failure to calculate total social costs & $\begin{array}{l}\text { Some RIAs calculate only direct compliance } \\
\text { costs, not other costs to society or the } \\
\text { nonregulated community. }\end{array}$
\end{tabular}

Failure to calculate full time stream of costs and benefits

Only costs and benefits for first and last year of study time period were shown.

Follow OMB guidance more fully. Analyze other reasonable regulatory options to determine the effect that a statutory constraint has on regulatory efficiency.

Clearly reference all documents needed to evaluate costs and benefits of proposed regulation.

Follow OMB guidance more fully. Analyze all important risk trade-offs.

Monetize all benefits to greatest extent possible, even if values cannot be considered when making final regulatory decision.

Develop data to value nonuse and ecological diversity benefits. EPA is currently developing values of ecological benefits.

Follow OMB guidance more fully. Perform calculation when cost data exist; develop data if needed.

Follow OMB guidance more fully. Show full time stream of cost and benefits.

Two similar RIAs used different exposure duration estimates: one used the 50 th percentile exposure and the other used the 90th percentile Use consistent exposure estimates for similar studies. Written guidance may be helpful here.

exposure.

Inconsistent use of key parameter: exposure duration 
TABLE 3 - continued

Finding

Inconsistent use of key parameter: discount rate benefits.

Failure to consider latency effects of fatalities or illnesses

Lack of external peer review of cost-benefit analyses

Cancer fatalities that would be avoided as a result of implementing a regulatory alternative were shown as an average over each year of study. Latency effects were not considered.

Each program office is responsible for content of cost-benefit analysis; there is no internal EPA peer review process. Mechanism exists for external peer review but it is not fully implemented.
Recommendation

Follow OMB and EPA guidance more fully. All costs and benefits should be discounted. Discounting should be consistent for both costs and benefits.

Consider latency effects as recommended in OMB guidance. Fatalities may not appear for 20-30 years. Develop standard guidance for latency periods for fatalities and illnesses.

Institute more rigorous peer review of costbenefit analyses.

implemented.
a These findings are based upon a sample of 11 RIAs produced by EPA as well as interviews with EPA staff. The findings should not necessarily be viewed
as widespread problems in all RIAs. They illustrate the kinds of problems that can occur in cost-benefit analysis. 


\section{REFERENCES}

Arrow, K.J., et al., 1996, Benefit-Cost Analysis in Environmental, Health, and Safety Regulations, American Enterprise Institute Press, Washington, D.C.

Ballard, G., and L. Luben, 1996, personal communications from Ballard and Luben (U.S. Environmental Protection Agency, Office of Solid Waste, Washington, D.C.) to L. Poch (Argonne National Laboratory, Argonne, III.), October 28 and November 18.

Barbera, A.J., and V.D. McConnell, 1990, "The Impact of Environmental Regulations on Industry Productivity: Direct and Indirect Effects," Journal of Environmental Economics and Management, winter, pp. 50-65.

Clark, M., 1996, presentation made by Clark (EPA - OW) at U.S. Environmental Protection Agency, Washington, D.C., May 8.

Commission on Risk Assessment and Risk Management, 1996, "Risk Assessment and Risk Management in Regulatory Decision-Making," draft report, June 13, available from the Commission (529 14th St., NW, Suite 452, Washington, D.C.), by fax at 202-233-9540 or on the Internet [http://www.riskworld.com].

Eagles, T., 1996, personal communications from Eagles (U.S. Environmental Protection Agency, Office of Air and Radiation, Washington, D.C.) to L. Poch (Argonne National Laboratory, Argonne, III.), October 22 and November 12.

ENR, 1996, "Not All EPA Rules Are Being Seen by Outsiders, GAO Report Charges,"Engineering News Record, October 28.

EPA, 1983, Guidelines for Performing Regulatory Impact Analysis, EPA 230-01-84-003, U.S. Environmental Protection Agency, Office of Policy Analysis, December (reprinted March 1991 with revised appendixes).

EPA, 1987, EPA's Use of Benefit-Cost Analysis: 1981-1986, EPA 230-05-87-028, U.S. Environmental Protection Agency, Office of Policy, Planning, and Evaluation, August.

EPA, 1989, Exposure Factors Handbook, EPA 600 8-89 043, U.S. Environmental Protection Agency, Office of Health and Environmental Assessment, July.

EPA, 1991, "Guidance for Risk Assessment," attachment to memo from F. Habicht II to U.S. Environmental Protection Agency Assistant Administrators/Regional Administrators, dated February 26, 1992.

EPA, 1993a, Regulatory Impact Analysis of Final Effluent Limitations Guidelines and Standards for the Offshore Oil and Gas Industry, EPA 821-R-93-002, U.S. Environmental Protection Agency, Office of Water, January. 
EPA, 1993b, Guidance on the Preparation of Economic Analyses and Regulatory Impact Analyses in OPPT, U.S. Environmental Protection Agency, Office of Pollution Prevention and Toxics, January.

EPA, 1995a, Regulatory Impact Analysis of $\mathrm{NO}_{x}$ Regulations, U.S. Environmental Protection Agency, Office of Atmospheric and Indoor Air Programs, Acid Rain Division, December 8.

EPA, 1995b, Adverse Effects of Nitrogen Oxides NO and Benefits of Reduction, U.S. Environmental Protection Agency, Office of Atmospheric and Indoor Air Programs, Acid Rain Division, December.

EPA, 1995c, Regulatory Impact Analysis of the Supplemental Proposed Rule Applying Phase IV Land Disposal Restrictions to Newly Identified Mineral Processing Wastes, U.S. Environmental Protection Agency, Office of Solid Waste, December.

EPA, 1996, Regulatory Impact Analysis of the Phase III Land Disposal Restriction Final Rule, U.S. Environmental Protection Agency, Office of Solid Waste, February 15.

Executive Order 12291, 1981, "Federal Regulation" The White House, Office of the Press Secretary, February 17.

Executive Order 12866, 1993, "Regulatory Planning and Review," The White House, Office of the Press Secretary, September 30.

Hahn, R.W., 1996, "Regulatory Reform: What Do the Government's Numbers Tell Us?," conference paper presented at Reviving Regulatory Reform, American Enterprise Institute, January 17.

Hazilla, M., and R. J. Koop, 1990, "Social Cost of Environmental Quality Regulations: A General Equilibrium Analysis," Journal of Political Economy, vol. 98, no. 4, pp. 853-873.

Hopkins, T., 1996, "Risk Prioritization: Moving the Debate Forward," paper presented at Climate Change Policy, Risk Prioritization, and U.S. Economic Growth, American Council for Capital Formation, Center for Policy Research, September 11.

Office of Technology Assessment, 1994, Industry, Technology, and the Environment: Competitive Challenges and Business Opportumities, OTA-ITE-586, U.S. Congress, Washington, D.C., January.

OMB, 1996, Economic Analysis of Federal Regulations Under Executive Order No. 12866, Executive Office of the President, Office of Management and Budget, January 11.

OMB, 1992, Guidelines and Discount Rates for Benefit-Cost Analysis of Federal Programs, Circular No. A-94, Executive Office of the President, Office of Management and Budget, October 29.

Omenn, G., 1996, “The Presidential/Congressional Risk Commission's Comprehensive New Risk Management Framework for Environmental Regulatory Agencies," seminar presentation made at Argonne National Laboratory, Argonne, Ill., November 7. 
Patel, N., 1996, personal communications from Patel (U.S. Environmental Protection Agency, Office of Water, Washington, D.C.) to L. Poch (Argonne National Laboratory, Argonne, Ill.), November 15 and 18.

Podar, M., 1996, personal communication from Podar (U.S. Environmental Protection Agency, Office of Water, Washington, D.C.) to L. Poch (Argonne National Laboratory, Argonne, Ill.), October 24.

Risk Policy Report, 1996, "EPA Assessing Its Ecorisk, Noncancer Cost-Benefit Work," Inside Washington Publishers, Washington, D.C., pp. 14-15, June 14.

Rusin M., et al., 1996, "Analysis of the Costs and Benefits of Regulations: A Review of Historical Experience," American Petroleum Institute Discussion Paper 084R, December.

Snyder, B., 1996, personal communication from Snyder (U.S. Environmental Protection Agency, Office of Policy, Planning and Evaluation, Washington, D.C.) to L. Poch (Argonne National Laboratory, Argonne, III.), October 21. 